\title{
"Alô, Doutor!": estudo-piloto de intervençãa radiofônica de Educação em Saúde desenvolvida em uma área rural de Minas Gerais
}

\author{
I ${ }^{1}$ Maria Flávia Gazzinelli, ${ }^{2}$ Laura Gazzinelli Colares, ${ }^{3}$ Letícia Moreira Bernardino, \\ ${ }^{4}$ Lucas Henrique Lobato Araújo, ${ }^{5}$ Amanda Nathale Soares I
}

Resumo: O objetivo do estudo foi analisar os efeitos de um Programa de Educação em Saúde desenvolvido por graduandos de medicina, com o emprego do rádio sobre a construção de conhecimentos por parte dos ouvintes residentes em um município do interior de Minas Gerais. Tratase de estudo intervencional, com delineamento longitudinal e abordagem quantitativa, realizado na cidade de Gouveia, situada na região centrosul do Vale do Jequitinhonha, Minas Gerais, Brasil. Verificou-se que os participantes do estudo conhecem vários aspectos sobre dengue, parasitoses, DST/HIV/Aids, bem como sobre os efeitos do uso do álcool e do tabaco. Denotou-se, igualmente, que o programa de rádio desempenhou papel importante nas aprendizagens relacionadas aos agravos abordados, expandindo significativamente o percentual de acertos das questôes expostas. As considerações elucidadas apontam que a utilização de estratégias educativas legitimadas no cenário vivencial da população e pautadas em uma relação dialógica é essencial para a reconstrução de saberes fundamentada nos conhecimentos prévios dos educandos.

> Palavras-chave: educação em saúde; rádio; dengue; doenças parasitárias; doenças sexualmente transmissíveis.
1 Professora associada do Departamento de Enfermagem Aplicada da Escola de Enfermagem da Universidade Federal de Minas Gerais, Brasil. Endereço eletrônico: flaviagazzinelli@yahoo.com.br

${ }^{2}$ Médica residente em Psiquiatria, Hospital Municipal Odilon Behrens, Belo Horizonte, Brasil. Endereço eletrônico: lauracolares@yahoo.com.br

${ }^{3}$ Médica generalista, Faculdade de Ciências Médicas de Minas Gerais, Brasil. Endereço eletrônico: epinefrinamaxima@ yahoo.com.br

${ }^{4}$ Doutorando em Enfermagem, Escola de Enfermagem da Universidade Federal de Minas Gerais, Brasil. Endereço eletrônico: lucaslobato87@ gmail.com

${ }^{5}$ Mestranda em Enfermagem, Escola de Enfermagem da Universidade Federal de Minas Gerais, Brasil. Endereço eletrônico: mandinha0708@ yahoo.com.br
Recebido em: 16/11/2012. Aprovado em: 13/08/2013. 


\section{Introdução}

O sistema de saúde brasileiro passou por reformas significativas visando à construção de um novo paradigma da produção social da saúde (ALVES, 2005; BRASIL, 1988). Para responder a essa nova ordem organizacional, o Ministério da Saúde (MS) atribuiu ênfase ao nível de Atenção Primária à Saúde (APS), caracterizado por um conjunto de açôes que incluem práticas gerenciais, sanitárias, democráticas e participativas. Essas ações devem ser desenvolvidas sob a forma de trabalho em equipe, dirigidas a populaçōes de territórios bem delimitados, pelas quais se assume a responsabilidade sanitária (BRASIL, 2007).

Com o intuito de operacionalizar essas ações, iniciou-se, a partir dos anos 90, a implantação do Programa Saúde da Família (PSF), atualmente referenciado como Estratégia de Saúde da Família (ESF). Essa modalidade prioriza a promoção da saúde, a prevenção de doenças, o tratamento e a recuperação da saúde dos indivíduos e da família de forma integral e contínua.

Como tarefas fundamentais do processo de trabalho das equipes da APS, estão previstos o desenvolvimento de ações intersetoriais, integrando projetos sociais e setores afins voltados à promoção da saúde; o apoio a estratégias de fortalecimento da gestão local e do controle social; e o desenvolvimento de açôes educativas capazes de interferir no processo de saúde-doença da população e ampliar o controle social na defesa da qualidade de vida (BRASIL, 2007).

A educação em saúde, segundo o discurso das atuais políticas de saúde, é entendida como um processo de construção ou reconstrução do conhecimento que tem por enfoque contribuir para a autonomia das pessoas no seu cuidado, a cidadania e o exercício do controle social (BRASIL, 2009). Para tanto, ressaltase a necessidade do desenvolvimento de ações de educação em saúde sob uma perspectiva dialógica, emancipadora, participativa e criativa (BRASIL, 2007a).

A despeito dessa orientação, estudos atuais revelam que no cenário assistencial ainda prevalecem ações educativas em saúde que fogem do preconizado pelas políticas vigentes. Em geral, são práticas que priorizam a imposição de conhecimentos, não favorecem o diálogo, centram-se na transmissão verticalizada de saberes e são pouco preocupadas com o desenvolvimento da autonomia dos sujeitos (ALVES; AERTS, 2011; FIGUEIREDO; RODRIGUES-NETO; LEITE, 2010).

Entretanto, em simultâneo a essas intervenções normativas, é possível identificar hoje, no contexto da AP, iniciativas educacionais que, com o objetivo 
de romper com essa vertente tradicional, utilizam-se de estratégias diversas para o desenvolvimento do processo de educação em saúde. Pode-se afirmar, porém, que o emprego de diferentes estratégias não necessariamente atesta e assegura práticas que favoreçam a construção do conhecimento por meio do diálogo. Nesse contexto insere-se o presente estudo, cujo objetivo é analisar os efeitos de uma prática educativa radiofônica fundamentada no critério de dialogicidade sobre a produção de conhecimento pelos sujeitos envolvidos no processo.

A despeito dos vários recursos utilizados na condução das práticas educativas mencionados na literatura revisada, a efetividade do rádio no processo educacional tem sido abordada de modo pouco expressivo. Considerado um meio de comunicação popular, mesmo com o advento da tecnologia e o surgimento de novos meios de massa, o rádio segue sendo utilizado por grande parte da população, mostrando-se presente em $89 \%$ dos domicílios brasileiros (BRASIL, 2008). Com efeito, percebe-se que o rádio, nas zonas rurais, como meio de comunicação de massa, supera a televisão, com $83,2 \%$ de penetração, sendo considerado o veículo que melhor atinge as zonas rurais e as regiōes distantes (BRASIL, 2007b).

Por essa evidenciada abrangência, o rádio pode ser considerado veículo de excelência para a disseminação do conhecimento com vistas à melhoria da saúde da população, particularmente aquela que vive longe dos grandes centros urbanos, conforme Silva et al. (2006). Em seu estudo de revisão sistemática, os autores demonstram evidências de que a informação veiculada pelo rádio amplia o conhecimento de saúde das populações.

Essas evidências levaram à proposta do programa "Alô, Doutor!", concebido por estudantes do curso de Medicina em parceria com estudantes da Escola de Enfermagem. O pressuposto é o de que, para se desenvolver uma educação voltada para a democratização do acesso à informação, deve-se buscar romper com a assimetria entre diferentes conhecimentos, valorizando as competências argumentativas existentes em cada um deles. Nesse programa, por meio de conversas telefônicas, o usuário apresenta suas dúvidas ao profissional de saúde. Com o duplo propósito de entreter e incentivar a participação dos ouvintes, há um personagem fictício que interage com o profissional trazendo casos e questôes do senso comum.

Diante do exposto, o objetivo deste estudo é analisar os efeitos de um Programa de Educação em Saúde, com o emprego da comunicação por rádio, 
sobre a construção de conhecimentos por parte dos ouvintes residentes em um município do interior de Minas Gerais.

\section{Metodologia}

Este estudo, intervencional, com delineamento longitudinal e abordagem quantitativa, foi conduzido na cidade de Gouveia, situada na região centrosul do Vale do Jequitinhonha, Minas Gerais, município em que graduandos de Medicina da Faculdade de Ciências Médicas de Minas Gerais cursaram o internato da disciplina "Saúde Coletiva".

Para o desenvolvimento deste estudo, utilizou-se a estação de rádio municipal, denominada "Kobu", durante dois meses (entre abril e junho de 2011), para a veiculação do programa "Alô, Doutor!". Este teve edição semanal, no período matutino, com duração de 30 minutos e apresentação pelos estudantes de medicina. O programa continha temas de diversas especialidades médicas, de interesse tanto da população em geral como da população local, a saber: dengue, parasitoses, Aids e outras doenças sexualmente transmissíveis, álcool e tabagismo.

Apesar de o programa possuir alcance municipal, utilizou-se apenas a área de abrangência da unidade primária de saúde "Sol" para avaliação da efetividade da intervenção educativa. Justifica-se esse recorte por ser o local em que os graduandos atuavam diretamente. Dessa forma, eles poderiam reforçar o convite aos participantes para escutarem o programa.

Utilizou-se como instrumento de medida um formulário estruturado, composto por questôes baseadas nos temas que, escolhidos pelos profissionais de saúde da unidade prímaria de saúde, representaram as demandas dos usuários em grupos operativos anteriores. $\mathrm{Na}$ construção das questôes, e para facilitar o entendimento dos participantes, tomaram-se cuidados durante sua redação, conforme sugerido por Vieira (2009). Entre esses cuidados estão a utilização de linguagem clara e de fácil entendimento (avaliados pelo Índice de Facilidade de Leitura de Flesch); a opção por termos de conhecimento geral, ao contrário de termos técnicos; e a não utilização de frases negativas e de palavras de significado duplo. Ainda, a elaboração dessas questôes considerou a experiência dos autores na construção de questionários destinados à avaliação de atividades educativas (GAZZINELLI; LOBATO; MATOSO et al., 2010; GAZZINELLI; SOUZA; ARAÚJO, et al., 2012; LOBATO; MIRANDA; FARIA et al., 2012). 
Este estudo adotou o critério de amostragem por conveniência, tendo contado com a manifestação voluntária dos usuários da unidade primária de saúde "Sol". Os critérios de inclusão estabelecidos foram ser usuário dessa unidade e ter o hábito de escutar a rádio "Kobu" ao menos três vezes por semana. Dessa forma, o estudo contou com 28 participantes, que concordaram em assinar o Termo de Consentimento Livre e Esclarecido.

Os participantes foram convidados a responder a um formulário estruturado autoaplicável na semana que antecedeu o primeiro programa de rádio veiculado na rádio "Kobu" (Tempo 1). Posteriormente, esse formulário foi aplicado aos mesmos participantes na semana posterior ao último programa (Tempo 2). Os participantes leram todo o conteúdo do questionário para começar a respondêlo; em caso de dúvida no entendimento dos enunciados, o entrevistador era solicitado para esclarecimentos. Durante a condução do estudo, os graduandos encorajaram, semanalmente, os usuários a escutar o programa “Alô, Doutor!”. As entrevistas, com o emprego do formulário, foram realizadas na unidade primária de saúde ou por abordagem dos usuários em suas residências.

A pesquisa foi conduzida segundo as exigências da Resolução 196/96, com aprovação do Comitê de Ética em Pesquisa com Seres Humanos da Universidade Federal de Minas Gerais (CAAE 01148512.5.0000.5149).

\section{Análise de dados}

Os dados coletados foram inseridos no programa Microsoft Excel, versão 2010, com a realização de dupla entrada independente dos dados. A análise estatística ocorreu no software Statistical Package for Social Sciences, versão 17.0. Realizou-se a análise descritiva dos dados, expressos em média e desvio padrão quando variáveis quantitativas, e frequência absoluta e relativa quando variáveis qualitativas.

Posteriormente, foi criado um escore para avaliar a compreensão global de cada grupo de questôes dos respectivos temas avaliados. Esse escore corresponde ao somatório de acerto individual de cada questão e à divisão pelo total de questôes do grupo. Cada questão correta recebeu o valor "1", enquanto as avaliadas como erradas, o valor " 0 ". O resultado desse escore foi expresso em média e desvio padrão. Por fim, o escore de cada grupo temático foi comparado entre o Tempo 1 e o Tempo 2 pelo teste de Wilcoxon, sendo estabelecido nível de significância estatística de $5 \%$. 


\section{Resultados}

A amostra foi constituída por 23 mulheres $(82,1 \%)$ e 5 homens, com idade entre 16 e 68 anos (média: 41,07 anos, DP: 16,078). A maioria dos participantes tinha ensino fundamental $(53,6 \%)$, enquanto o restante tinha ensino médio $(35,7 \%)$ ou era analfabeto $(10,7 \%)$. Em relação à profissão, a maior parte dos participantes relatou ser "profissional do lar" (21,4\%), acompanhada por lojista, estudante e comerciante $(10,7 \%$ cada).

A televisão foi assinalada como a fonte de informação central $(60,4 \%)$, seguida do rádio $(35,7 \%)$. Apesar de não ser considerada a principal fonte de informação, a rádio local é ouvida diariamente pela maioria dos participantes $(64,3 \%)$, enquanto $25 \%$ o fazem de quatro a seis vezes por semana.

Os dados da tabela 1 indicam o percentual médio de acerto do grupo de questôes concernentes à dengue, às parasitoses, às doenças sexualmente transmissíveis (DST/HIV/Aids), ao álcool e ao tabaco, antes e após o processo educativo. A comparação das médias de acertos evidenciou acréscimo estatisticamente significativo em todos os grupos temáticos $(\mathrm{p} \leq 0,05)$, com exceção do grupo que representa o tema DST ( $>0,05)$ (tabela 1). Ressalta-se que, em todos os grupos temáticos, a porcentagem média de acerto foi superior a $65 \%$ e $75 \%$ nos Tempos 1 e 2 , respectivamente.

Tabela 1. Porcentagem média de acertos e mediana nos Tempos 1 e 2, distribuídas por temas

\begin{tabular}{|c|c|c|c|c|}
\hline \multirow{2}{*}{ Tema } & \multicolumn{2}{|c|}{ Mediana (média) } & \multirow{2}{*}{$\mathbf{z}^{*}$} & \multirow{2}{*}{$p^{* *}$} \\
\hline & Tempo 1 & Tempo 2 & & \\
\hline Dengue & $62,5 \%(68,21 \%)$ & $75 \%(78,30 \%)$ & $-2,075$ & 0,038 \\
\hline Parasitoses & $71,42 \%(82,14 \%)$ & $85,71 \%(90,48 \%)$ & $-2,013$ & 0,044 \\
\hline DST & $80 \%(84 \%)$ & $80 \%(87,33 \%)$ & $-1,192$ & 0,233 \\
\hline Álcool/Tabaco & $77,7 \%(79,37 \%)$ & $88 \%(92,30 \%)$ & $-1,990$ & 0,047 \\
\hline
\end{tabular}

${ }^{*}$ Teste de Wilcoxon ${ }^{* *}$ Nível de Significância: 5\%

Fonte: Pesquisa de Campo

A partir dos dados expostos na tabela 2, evidencia-se que todas as questóes sobre a dengue exibiram porcentagem de acerto superior a $50 \%$, antes do processo 
educativo, com exceção do conhecimento relativo à inexistência de imunização ativa contra dengue $(46,6 \%)$.

Com relação ao conhecimento sobre o modo de transmissão da doença, a existência de mais de um tipo de vírus e o turno de maior incidência de ataque do Aedes aegypti (tabela 2), observa-se aumento do percentual de acerto no Tempo 2, ou seja, após a intervenção. Destaca-se que a noção da vulnerabilidade à reinfecção apresentou maior elevação do percentual de acerto entre todas as questôes, atingindo a totalidade de acerto após a intervenção educativa. Apenas em duas questões não foi detectado aumento no número de acertos, quais sejam, a que aborda a existência de vacina contra a dengue, em que houve uma redução do percentual de acertos, e a que especifica o lixo como local onde o mosquito deposita seus ovos, em que o número de acertos manteve-se o mesmo.

Tabela 2. Porcentagem de acerto das questóes constituintes do tema "Dengue" antes e após intervenção educativa

\begin{tabular}{lcc}
\hline \multicolumn{1}{c}{ Questão } & \% Pré-teste & \% Pós-teste \\
\hline A dengue é transmitida por mais de um tipo de vírus? & $58 \%$ & $66 \%$ \\
\hline Quem já teve dengue pode pegar novamente? & $73 \%$ & $100 \%$ \\
\hline $\begin{array}{l}\text { A dengue é transmitida por contato com secreção de } \\
\text { algum doente? }\end{array}$ & $60 \%$ & $66,6 \%$ \\
\hline $\begin{array}{l}\text { A dengue é transmitida por picada do mosquito } \\
\text { contaminado? }\end{array}$ & $93,3 \%$ & $100 \%$ \\
\hline Existe vacina contra a dengue? & $46,6 \%$ & $33,3 \%$ \\
\hline O mosquito da dengue ataca mais durante a noite? & $60,6 \%$ & $80,0 \%$ \\
\hline O mosquito da dengue põe seus ovos no lixo? & $53,3 \%$ & $53,3 \%$ \\
\hline O mosquito da dengue põe seus ovos na água parada? & $100 \%$ & $100 \%$ \\
\hline
\end{tabular}

Fonte: Pesquisa de Campo

Os resultados apresentados na tabela 3 demonstram que todas as questôes relativas às parasitoses apresentaram porcentagem de acerto superior a 65\%, no Tempo 1, exceto o conhecimento da possibilidade de infecção por vermes nadando em água limpa (33,3\%). Nesse ponto específico, merece realce o considerável reforço no número de acertos, no Tempo 2, após a intervenção. 
Evidencia-se, em todas as questões, após a intervenção educativa, percentual de acerto superior ao observado antes da intervenção educativa, com exceção da noção sobre a possibilidade de adquirir parasitose ao se andar descalço e a não exclusividade dessas doenças ao ambiente rural, que mantiveram a totalidade de acerto nos dois momentos de coleta de dados (tabela 3). Outra exceção foi o decréscimo do percentual de acerto quanto à possibilidade de se adquirir parasitose ao ingerir água, que passou de 100\%, no Tempo 1, para 91,6\%, no Tempo 2. Destaca-se o importante aumento de acertos relacionado à noção de que, embora tenham tratamento, as verminoses podem tornar-se perigosas.

Tabela 3. Porcentagem de acerto das questôes constituintes do tema "Parasitoses" antes e após intervenção educativa

\begin{tabular}{lcc}
\hline \multicolumn{1}{c}{ Questão } & \% Pré-teste & \% Pós-teste \\
\hline Só pego verme e parasitas se comer comida estragada? & $100 \%$ & $100 \%$ \\
\hline Nadar em água limpa pega verme? & $33,3 \%$ & $66,6 \%$ \\
\hline $\begin{array}{l}\text { Verme e parasitas não são perigosos porque é fácil de } \\
\text { tratar? }\end{array}$ & $75 \%$ & $91,6 \%$ \\
\hline Você pode ter vermes e parasitas e sentir nada? & $66,6 \%$ & $83 \%$ \\
\hline Você pode pegar parasitas bebendo água? & $100 \%$ & $91,6 \%$ \\
\hline Você pode pegar verme andando descalço? & $100 \%$ & $100 \%$ \\
\hline Só tem verme na roça? & $100 \%$ & $100 \%$ \\
\hline
\end{tabular}

Fonte: Pesquisa de Campo

A partir dos dados expostos na tabela 4, evidencia-se que todas as questôes referentes às DST/HIV/Aids exibiram porcentagem de acerto superior a 50\% antes do processo educativo. Observa-se que o percentual de acerto, após a intervenção educativa, foi superior ao achado antes desse processo na maioria das questões, com dois tipos de exceção. $\mathrm{O}$ primeiro refere-se às questões que abordaram a necessidade do uso de preservativos na prevenção de DST, os modos de contágio do vírus HIV e a impossibilidade preditiva de diagnóstico da AIDS pelo fenótipo, que apresentaram 100\% de acerto nos dois momentos (tabela 4). O outro tipo refere-se ao conhecimento sobre a impossibilidade de a pílula anticoncepcional evitar a infecção por DST, que apresentou diminuição do percentual de acerto após a intervenção educativa (tabela 4). 
Destaca-se, no grupo de questões, maior elevação no percentual de acerto na questão que abordava a possibilidade de pessoas portadoras do vírus HIV manterem relações sexuais seguras (tabela 4).

Tabela 4. Porcentagem de acerto das questões constituintes do tema "Doenças Sexualmente Transmissíveis" antes e após intervenção educativa

\begin{tabular}{|c|c|c|}
\hline Questão & $\%$ Pré-teste & \% Pós-teste \\
\hline $\begin{array}{l}\text { O uso de pílula anticoncepcional evita pegar } \\
\text { AIDS e outras DSTs? }\end{array}$ & $93,3 \%$ & $86,6 \%$ \\
\hline Para evitar pegar AIDS tem que usar preservativo? & $100 \%$ & $100 \%$ \\
\hline A AIDS tem cura? & $80 \%$ & $86,6 \%$ \\
\hline $\begin{array}{l}\text { Apenas relações homossexuais podem passar o } \\
\text { vírus da AIDS? }\end{array}$ & $100 \%$ & $100 \%$ \\
\hline $\begin{array}{l}\text { Aids se pega com aperto de mão, abraço, } \\
\text { beijo no rosto? }\end{array}$ & $100 \%$ & $100 \%$ \\
\hline Aids se pega com contato com lágrima ou saliva? & $66,6 \%$ & $73,3 \%$ \\
\hline $\begin{array}{l}\text { Apenas } 1 \text { (um) relacionamento sexual pode } \\
\text { transmitir DSTs? }\end{array}$ & $86,6 \%$ & $93 \%$ \\
\hline $\begin{array}{l}\text { Pacientes com o vírus da AIDS podem ter relação } \\
\text { sexual segura? }\end{array}$ & $53 \%$ & $60 \%$ \\
\hline $\begin{array}{l}\text { É possível estar com uma DST e não apresentar } \\
\text { sintomas? }\end{array}$ & $60 \%$ & $80 \%$ \\
\hline $\begin{array}{l}\text { Eu posso saber se uma pessoa tem AIDS pela sua } \\
\text { aparência? }\end{array}$ & $100 \%$ & $100 \%$ \\
\hline
\end{tabular}

Fonte: Pesquisa de Campo

A partir da tabela 5, observa-se que todas as questões sobre o álcool e o tabaco apresentaram $100 \%$ de acerto após a intervenção educativa e valores superiores a $70 \%$ antes do processo educacional. A única exceção a esse quadro foi creditada ao conhecimento sobre a relação entre diminuir o número de cigarros diários e evitar as doenças relacionadas ao tabaco. Nessa questão, observa-se baixo percentual de acerto no momento inicial e diminuição desse valor após a intervenção educativa (tabela 5). 

antes e após intervenção educativa

\begin{tabular}{lcc}
\hline \multicolumn{1}{c}{ Questão } & \% Pré-teste & \% Pós-teste \\
\hline O fumante pode ter rugas mais precoces? & $78,6 \%$ & $100 \%$ \\
\hline O cigarro pode causar impotência sexual? & $85,7 \%$ & $100 \%$ \\
\hline $\begin{array}{l}\text { O único câncer que o cigarro pode provocar } \\
\text { é o de pulmão? }\end{array}$ & $84,6 \%$ & $100 \%$ \\
\hline $\begin{array}{l}\text { Diminuir o no de cigarros/dia evita as doenças } \\
\text { relacionadas ao cigarro? }\end{array}$ & $38,4 \%$ & $30,7 \%$ \\
\hline $\begin{array}{l}\text { Fumar apenas 1 (um) cigarro por dia faz mal? } \\
\text { Os não fumantes podem desenvolver doenças } \\
\text { relacionadas ao cigarro? }\end{array}$ & $71,4 \%$ & $100 \%$ \\
\hline Beber melhora a atividade sexual? & $85,7 \%$ & $100 \%$ \\
\hline O alcoolismo tem tratamento? & $82,3 \%$ & $100 \%$ \\
\hline $\begin{array}{l}\text { Um alcoólatra após tratar pode beber de vez } \\
\text { em quando? }\end{array}$ & $84,6 \%$ & $100 \%$ \\
\hline
\end{tabular}

Fonte: Pesquisa de Campo

\section{Discussão}

Observou-se que os residentes de Gouveia participantes do estudo conhecem vários aspectos sobre a dengue, as parasitoses, as DST/HIV/AIDS, bem como sobre os efeitos do uso do álcool e do tabaco. Por sua presença incontornável na vida cotidiana da grande maioria das pessoas, esses assuntos são hoje de domínio público. Há ainda a importância crescente das mídias e das campanhas de saúde pública na disseminação e na socialização de informações no campo da saúde.

Este estudo permitiu identificar o quanto o programa de rádio "Alô, Doutor!" desempenhou papel importante nas aprendizagens relacionadas aos agravos abordados. Possibilitou a confirmação da hipótese segundo a qual ambientes de diálogo em que se busca romper com as assimetrias entre os diferentes tipos de conhecimento - saber comum, saber popular e conhecimento científico - são potencialmente eficazes na produção de aprendizagens pela mediação oportunizada entre o sujeito e o objeto do conhecimento a ser construído (SANTOS, 2000). 
No programa de rádio, a partir das indagações que surgiam no momento, abria-se espaço para que os conhecimentos comuns das pessoas entrassem gradualmente em confronto. Ao se interpenetrarem, eles revestiam-se de novos sentidos, determinando a produção de novos conhecimentos. Além disso, por meio de indagações sobre "o que", "por que" e "como", às quais se buscava responder com relatos e conhecimentos elaborados, conformou-se um espaço de coprodução (SANTOS, 2000).

Outras experiências de educação que relatam a utilização do rádio destacam, igualmente, a potencialidade desse recurso comunicacional na produção de conhecimentos em saúde nas coletividades por meio da articulação entre o saber popular e o conhecimento técnico-científico, representado pelo profissional de saúde. Ressaltam, também, a favorável penetrabilidade desse veículo nas populações, sobretudo nas camadas mais pobres, permitindo melhorias significativas no processo ensino-aprendizagem (RODRIGUES et al., 2012; PRADO et al., 2011; PRADO, 2007; JURBERG; MACCHIUTE, 2007; PERKINS et al., 2007; CABRERA-PIVARAL et al., 2002; ALBUQUERQUE; STOTZ, 2004; MATOS; MENEGUETTI; GOMES, 2009; GOMES; MERHY, 2011).

Denotou-se que os conhecimentos acerca da dengue apresentados pelos participantes deste estudo, de modo geral, representam saberes prévios corretos quanto à doença e ao seu vetor. Essa verificação também foi feita em outros estudos que investigaram o conhecimento e as representaçōes da população sobre esse tema. Pode-se atribuir esse achado às campanhas educativas, principalmente televisivas e radiofônicas, à experiência próxima com a doença e à orientação domiciliar realizada pelos agentes comunitários de saúde e pelos agentes de combate a endemias (SANTOS; CABRAL; AUGUSTO, 2011; LEFEVRE et al., 2007; CLARO; TOMASSINI; ROSA, 2004).

Os conhecimentos prévios da maioria dos pesquisados, sobretudo os relacionados ao turno de maior incidência de ataque do Aedes aegypti e à transmissibilidade pela picada de inseto contaminado, também foram observados em um estudo realizado em Cabo de Santo Agostinho/Pernambuco. Nesse estudo, $71 \%$ dos participantes referiram saber dos hábitos diurnos do mosquito e $98 \%$ explicitaram o conhecimento acerca da transmissão durante a picada (SANTOS; CABRAL; AUGUSTO, 2011). Embora antes da intervenção já se verificasse alto percentual de acerto sobre essas questôes, o processo educativo 
radiofônico mostrou-se eficaz para expandir o conhecimento dos participantes acerca dos hábitos do vetor e da transmissibilidade da doença, corroborando a importância do rádio e de uma estratégia dialógica na educação em saúde.

A dificuldade manifesta pelos participantes, mesmo após a intervenção educativa, quanto à compreensão da relação entre o lixo e a deposição de ovos do mosquito mostrou-se presente, igualmente, em um estudo realizado em São Sebastião/São Paulo. Nessa pesquisa, revelou-se que a população associa a água suja, acumulada, empoçada ou pluvial à criação do mosquito, demonstrando a limitada discriminação do tipo e da modalidade de coleção de água mais apropriados para a criação do inseto (LEFEVRE et al., 2007).

A concepção acerca da sujeira e dos seus efeitos nas condições de saúde e doença situa-se na ordem do simbólico e se configura no interior de um sistema cultural de ordenações e classificações sistemáticas que provê, antecipadamente, um padrão de ideias e valores que medeia a experiência dos sujeitos (DOUGLAS, 1976). Nesse sistema, a sujeira representa, em essência, a desordem, o que permite remetê-la à doença, também considerada, na estrutura cultural, um desarranjo da ordem orgânica. Nesse sentido, a associação entre lixo e deposição de ovos, revelada neste estudo, encontra-se fundada nas raízes culturais que se impõem à vida dos indivíduos. Isso desvela que a díade limpeza-doença é um pressuposto incoerente com a história vivencial dos sujeitos e da coletividade, tendendo, portanto, a ser rejeitada (DOUGLAS, 1976).

Ainda quanto aos conhecimentos sobre a dengue, outro aspecto que merece destaque refere-se à redução do número de acertos, após a intervenção educativa, sobre a inexistência de vacina contra a doença. Esse achado pode não representar uma inversão conceitual incorreta mediada pela intervenção radiofônica, uma vez que os conhecimentos prévios podem se mostrar frágeis e, embora sejam apresentados como um acerto à pergunta do questionário no Tempo 1, podem não ser um saber verdadeiramente construído. Nesse sentido, a intervenção mostrou-se insuficiente para reconstruir, adequadamente, os conhecimentos sobre a inexistência de vacina contra a dengue, o que suscita reflexões sobre a adequação da linguagem utilizada e a ênfase dada a esse assunto especificamente.

Ao se considerar, ainda, a possível fragilidade dos conhecimentos prévios e as limitações da intervenção para a construção dos saberes sobre a inexistência da 
imunização contra a dengue, é plausível se pensar que os indivíduos podem ter sido influenciados pela existência de vacinas para outras doenças virais, como, por exemplo, a gripe.

No que tange aos conhecimentos dos pesquisados acerca das parasitoses, denotase alta porcentagem de acertos antes da intervenção educativa, revelando que se trata de informações amplamente presentes nas comunidades, conforme verificado em outros estudos (SIQUEIRA; FIORINI, 1999; PEDRAZZANI et al., 1990). Esse dado também foi encontrado em pesquisa que investigou os conhecimentos do público infantil sobre essa temática (LANA; OLIVEIRA, 2009).

A dificuldade de compreensão referente à possibilidade de infecção por vermes a partir da água limpa também foi verificada em um estudo realizado em Santo Antônio de Jesus/Bahia, em que se revelou a forte associação popular entre parasitoses e ambientes sujos (NORONHA et al., 1995). A porcentagem de acertos sobre essa questão dobrou após a intervenção radiofônica, o que demonstra melhoria na concepção sobre a contaminação, mas se manteve em um patamar inferior às demais perguntas. Essa limitação compreensiva ratifica a concepção de que o sistema cultural define perspectivas elementares acerca da sujeira, as quais conduzem os indivíduos a tratar como inoportuna a relação entre água limpa e verminoses e, então, negligenciar espaços potencialmente contaminados.

A periculosidade atribuída às parasitoses, aumentada após a intervenção educativa, pode mostrar-se desacompanhada da perspectiva de seu potencial de fatalidade, como demonstrado no estudo, acima referido, desenvolvido na Bahia. Neste, verificou-se que, embora seja possível se reconhecer como perigosa uma determinada parasitose, ao vivenciá-la em seu cotidiano, muitas vezes, desconsiderase que ela pode representar uma ameaça à vida (NORONHA et al., 1995).

$\mathrm{O}$ conhecimento sobre a possibilidade de adquirir parasitoses ao ingerir água mostrou-se reduzido após a intervenção educativa. Essa redução pode ser atribuída, como já referido anteriormente, à fragilidade conceitual prévia e, nesse sentido, à insuficiência da intervenção radiofônica. Em paralelo, pode-se ressaltar, nesse achado, a dificuldade de os indivíduos conferirem à água ingerida o potencial de contaminação, possivelmente pela descrença na existência de microorganismos na água que se bebe e, portanto, pela dificuldade de associação entre limpeza e doença. 
No que tange às DST/HIV/Aids, os saberes dos participantes deste estudo mostraram-se, em geral, adequados previamente à intervenção educativa, o que foi igualmente verificado em outros estudos, sobretudo no que se refere aos conhecimentos sobre a prevenção das DST (OLIVI; SANTANA; MATHIAS, 2008; FERNANDES et al., 2000). Evidenciou-se, depois da intervenção radiofônica, aumento no percentual de acertos referentes à possibilidade de uma pessoa portadora do vírus HIV manter relações sexuais seguras. Entretanto, permaneceu a concepção, em $40 \%$ dos participantes, de que o indivíduo portador de HIV não pode dar continuidade a sua vida sexual de modo seguro, o que pode ser atribuído à descrença na capacidade preventiva do preservativo, ao estigma e ao medo gerados diante de uma pessoa infectada.

Observou-se também, que, após a intervenção educativa, houve um aumento do percentual de acertos quanto à impossibilidade de transmissão da Aids por meio do contato com lágrima ou saliva. Entretanto, 26,7\% dos participantes permaneceram com a crença na transmissibilidade do HIV por meio dessas secreçôes. Dado semelhante foi encontrado em um estudo realizado com universitários do interior de São Paulo, em que 22\% dos pesquisados revelaram acreditar na possibilidade transmissiva do vírus por meio da saliva (CANO et al., 2007).

Denotou-se, ainda, no presente estudo, que 100\% dos participantes consideraram o preservativo um meio de evitar a contaminação pelo HIV. Entretanto, em um estudo realizado em Campinas/São Paulo, não se observou essa concepção na totalidade dos pesquisados, os quais referenciaram o uso da camisinha, sobretudo, como método anticoncepcional (FERNANDES et al., 2000). Denotou-se, ainda, que todos os pesquisados desconsideraram a possibilidade de se reconhecer uma pessoa com Aids por meio de sua aparência, o que não foi observado em um estudo desenvolvido em Goiânia/Goiás, em que $23,9 \%$ dos participantes afirmaram ser possível identificar um indivíduo portador de Aids pelo seu fenótipo (COELHO et al., 2011).

Ainda sobre DST/HIV/Aids, verificou-se uma redução do percentual de acerto, após a intervenção educativa, sobre a impossibilidade de a pílula anticoncepcional evitar a aquisição de Aids e outras DSTs. Esse achado pode revelar, como já colocado previamente, que a fragilidade conceitual não conseguiu ser reconsiderada, mesmo após a intervenção radiofônica. Diante disso, coloca-se a possibilidade de que, ao 
considerarem o preservativo um método anticoncepcional e também capaz de evitar a transmissibilidade da Aids e de outras DSTs, os indivíduos, guiados pela ideia do termo "anticoncepcional", apresentado na intervenção e no questionário, podem ter atribuído à pílula o mesmo caráter preventivo.

Os conhecimentos prévios dos participantes acerca do álcool e do tabaco revelaram compreensão sobre essas temáticas, exceto no que tange à relação entre a quantidade de cigarros diários e a redução do risco de desenvolver doenças relacionadas ao tabaco, cujo percentual de acerto diminuiu após a intervenção radiofônica. As demais questôes registraram 100\% de acerto posteriormente ao processo educativo, ratificando a importância do recurso radiofônico utilizado para a produção de conhecimentos em saúde.

O álcool e o tabaco situam-se em um espaço de destaque na sociedade moderna, por serem considerados, juntos ao sedentarismo e à alimentação inadequada, fatores de risco para doenças crônicas não transmissíveis, muito representativas na atualidade. Verificou-se, em um estudo desenvolvido em Pelotas/Rio Grande do Sul, que $98 \%$ dos pesquisados reconhecem a relação entre tabagismo e câncer de pulmão (BORGES et al., 2009). Complementarmente, os participantes do presente estudo reconheceram, em sua totalidade, após a intervenção educativa, que, além do câncer de pulmão, altamente referido, o tabagismo pode causar outros tipos de câncer.

Ainda sobre o tabagismo, mesmo antes da intervenção radiofônica, a maioria dos participantes afirmou, de forma correta, que as pessoas não fumantes podem desenvolver doenças relacionadas ao cigarro. Essa verificação, embora manifesta em maior proporção nesta pesquisa, aproxima-se de um estudo realizado com pais de crianças internadas em uma Unidade de Terapia Intensiva, segundo o qual $70 \%$ dos pesquisados acreditavam que o fumo poderia afetar a saúde das crianças (TANNI et al., 2010). A expansão desse conhecimento para $100 \%$ dos participantes, após a intervenção educativa, mostra-se essencial para reduzir os danos à saúde, com diminuição, sobretudo, dos impactos no desenvolvimento infantil e das complicações respiratórias no indivíduo adulto (REICHERT et al., 2008).

Outro achado que merece destaque refere-se à redução do percentual de acertos sobre o impacto da redução do número de cigarros por dia na prevenção 
das doenças relacionadas ao tabagismo. Ao se considerar que essa questão já apresentava baixo percentual de acerto antes da intervenção radiofônica, ressaltase, já previamente, a dificuldade da construção desse conhecimento por parte dos indivíduos participantes deste estudo. Sobre esse aspecto, a intervenção mostrouse insuficiente para a (re)elaboração desse saber.

Destaca-se, aqui, que a formulação da pergunta - "Diminuir o no de cigarros/ dia evita as doenças relacionadas ao cigarro?” - pode ter gerado ambiguidade, uma vez que a diminuição do número de cigarros por dia reduz as chances do desenvolvimento de patologias relacionadas ao tabagismo e, entretanto, não as evita. Assim, a resposta “não", esperada para essa pergunta, encobre a possibilidade de se reduzir a probabilidade de algumas doenças pela diminuição do número de cigarros por dia. Já a resposta "sim", embora incorreta, pode ter representado para os indivíduos respondentes a associação entre redução do número de cigarros e diminuição da probabilidade de doenças a eles relacionadas.

Quanto ao uso de álcool, todos os participantes deste estudo, após a intervenção radiofônica, responderam, corretamente, que a bebida não melhora o desempenho sexual, o que também foi verificado em um estudo desenvolvido com universitários do sexo masculino, em que estes reconheceram que o uso abusivo de álcool pode levar à disfunção erétil e à ejaculação precoce (MARTINS; VAISBERG, 2009).

O reconhecimento da existência de tratamento para o alcoolismo, já verificado majoritariamente pelos participantes antes da intervenção educativa, contrapõe os dados observados em um estudo realizado com estudantes da Escola de Enfermagem de Ribeirão Preto (Universidade de São Paulo). Neste, 74\% dos pesquisados não responderam ou desconhecem os tipos de tratamentos destinados aos pacientes com problemas de uso abusivo do álcool (LUIS; PILLON, 2003).

Denota-se, em diferentes estudos, que a aquisição de conhecimentos não necessariamente remete a uma transformação comportamental (SANTOS; CABRAL; AUGUSTO, 2011; OLIVI; SANTANA; MATHIAS, 2008). Nesse sentido, o presente estudo pode revelar-se limitado frente às necessárias mudanças de atitude para a melhoria das condições de saúde da população em análise. Entretanto, para tangenciar uma mudança das açóes, deve-se incidir, primariamente, na ordem do simbólico, do conhecimento e das representações, o que permite considerar este estudo relevante para a abordagem das temáticas em foco. 


\section{Considerações finais}

Este estudo ressalta a importância da utilização do rádio como meio para a construção de conhecimentos e para a evolução conceitual em saúde, dada sua autêntica presença e favorável penetrabilidade nas comunidades, sobretudo nas que menos dispõem de recursos socioeconômicos.

Destaca-se, igualmente, que a aproximação e a interação recíproca entre os saberes do senso comum e o conhecimento técnico-científico, mediadas por estratégias pedagógicas pautadas no diálogo, tornam-se necessárias para contemplar os princípios da educação em saúde explícitos no vigente discurso teórico-político de saúde e para favorecer melhorias nas condiçōes de saúde da população.

As considerações elucidadas apontam que a utilização de estratégias educativas legitimadas no cenário vivencial da população e pautadas em uma relação horizontalizada é essencial para a reconstrução de saberes fundamentada nos conhecimentos prévios e, por conseguinte, para a sensibilização individual e coletiva acerca das ações compatíveis com o conjunto de saberes disponíveis sobre as condições de saúde e doença. ${ }^{1}$

\section{Referências}

ALBUQUERQUE, P.C., STOTZ, E.N. A educação popular na atenção básica à saúde no município: em busca da integralidade. Interface: Comunic., Saúde, Educ. São Paulo, v. 8, n. 15, p. 259-74, 2004.

ALVES, G.G., AERTS, D. As práticas educativas em saúde e a Estratégia de Saúde da Família. Cienc Saude Colet. Rio de Janeiro, v. 16, n. 1, p. 319-25, 2011.

ALVES, V. S. A health education model for the Family Health Program: towards comprehensive health care and model reorientation. Interface: Comunic., Saúde, Educ. São Paulo, v. 9, n. 16, p. 39-52, 2005.

BORGES, T.T. et al. Conhecimento sobre fatores de risco para doenças crônicas: estudo de base populacional. Cad Saúde Pública. Rio de Janeiro, v. 25, n. 7, p. 1511-20, 2009.

BRASIL. Comitê Gestor da Internet no Brasil. Pesquisa sobre o uso das tecnologias da informação e da Comunicação no Brasil: TIC Domicílios e TIC Empresas 2007. 2a Ed. São Paulo: Comitê Gestor da Internet no Brasil, 2008.

Constituição. Constituição da República Federativa do Brasil. Brasília, DF: Senado Federal, 1988. 

de março de 2006. Aprova a Política Nacional de Atenção Básica, estabelecendo a revisão de diretrizes e normas para a organização da Atenção Básica para o Programa Saúde da Família (PSF) e o Programa Agentes Comunitários de Saúde (PACS). Diário Oficial da República Federativa do Brasil, 2007a.

Ministério das Telecomunicações. Comissão de Ciência, Tecnologia, Inovação, Comunicação e Informática. Rádio digital. 2007b. Disponível em: <http://www.senado. gov.br/web/comissoes/cct/ap/AP20071122_MinCom_RobertoPintoMartins.pd> Acesso em: 03 nov 2012.

- Ministério da Saúde. Secretaria de Gestão do Trabalho e da Educação na Saúde. Glossário temático: gestão do trabalho e da educação na saúde. Brasília: Ministério da Saúde, 2009.

CABRERA-PIVARAL, C. E. et al. Evaluación de dos estrategias de educación nutricional vía radio em Guadalajara, México. Cad Saúde Pública. Rio de Janeiro, v. 18, n. 5, p. 1289-94, 2002. CANO, M.A.T. et al. O conhecimento de jovens universitários sobre AIDS e sua prevenção. Rev Eletr Enf. Goiânia, v. 9, n. 3, p. 748-58, 2007.

CLARO, L.B.L.; TOMASSINI, H.C.B.; ROSA, M.L.G. Prevenção e controle do dengue: uma revisão de estudos sobre conhecimentos, crenças e práticas da população. Cad Saúde Pública. Rio de Janeiro, v. 20, n. 6, p. 1447-57m, 2004.

COELHO, R.F.S. et al. Conhecimentos e crenças sobre doenças sexualmente transmissíveis e HIV/AIDS entre adolescentes e jovens de escolas públicas estaduais da região oeste de Goiânia. Rev Patol Trop. Goiânia, v. 40, n. 1, p. 56-66, 2011.

DOUGLAS, M. Pureza e perigo. São Paulo: Perspectiva, 1976. 216 p.

FERNANDES, M.A.S. et al. Conhecimento, atitudes e práticas de mulheres brasileiras atendidas pela rede básica de saúde com relação às doenças de transmissão sexual. Cad Saúde Pública. Rio de Janeiro, v. 16, n. sup. 1, p. 103-12, 2000.

FIGUEIREDO, M.F.S.; RODRIGUES-NETO, J.F.; LEITE, M.T.S. Modelos aplicados às atividades de educação em saúde. Rev Bras Enferm. Brasília, v. 63, n. 1, p. 117-21, 2010.

GAZZINELLI, M.F. et al. Health education through analogies: preparation of a community for clinical trials of a vaccine against hookworm in an endemic area of Brazil. PLoS Negl. Trop. Diseases. San Francisco, v. 4, n. 7, p. 749-762, 2010.

GAZZINELLI, M.F. et al. Theater in the education of children and teenagers participating in a clinical trial..Rev de Saúde Pública,.São Paulo, v. 46, n. 6, p. 999-1006, 2012.

GOMES, L.B.; MERHY, E.E. Compreendendo a Educação Popular em Saúde: um estudo na literatura brasileira. Cad Saúde Pública. Rio de Janeiro, v. 27, n. 1, p. 7-18, 2011.

JURBERG, C.; MACCHIUTE, B. Câncer nas ondas do rádio. Rev Bras Cancerol. Rio de Janeiro, v. 53, n. 3, p. 291-6, 2007. 
LANA, I.L.; OLIVEIRA, M.A. Percepção de risco de contaminação por parasitas nos alunos de ensino fundamental do município de São José dos Campos. In: XII ENCONTRO LATINO AMERICANO DE INICIAÇÃO CIENTÍFICA e VIII ENCONTRO LATINO AMERICANO DE PÓS GRADUAÇÃO, 2009, Paraíba. Anais... Paraíba: 2009. p. 1-6.

LEFEVRE, A.M.C. et al. Representações sobre dengue, seu vetor e ações de controle por moradores do Município de São Sebastião, Litoral Norte do Estado de São Paulo, Brasil. Cad Saúde Pública. Rio de Janeiro, v. 23, n. 7, p. 1696-1706, 2007.

LOBATO, L. et al. Development of cognitive abilities of children infected with helminths through health education. Rev Soc Bras Med Trop. Uberaba, v. 45, n. 4, p. 514-19, 2012.

LUIS, M.A.V.; PILLON, S.C. O conhecimento dos alunos de enfermagem sobre álcool e drogas. Rev Eletr Enf. Goiânia, v. 5, n. 1, p. 21-7, 2003.

MARTINS, P.C.R.; VAISBERG, T.M.J.A. Dificuldades sexuais masculinas e imaginário coletivo de universitários. Barbarói. Santa Cruz do Sul, n. 31, p. 18-35, 2009.

MATOS, M.R.; MENEGUETT, L.C.; GOMES, A.L.Z. Uma experiência em comunicação e saúde. Interface - Comunic., Saúde, Educ. São Paulo, v. 13, n. 31, p. 437-47, 2009.

NORONHA, C.V. et al. Uma concepção popular sobre a esquistossomose mansônica: os modos de transmissão e prevenção na perspectiva de gênero. Cad Saúde Pública. Rio de Janeiro, v. 11, n. 1, p. 106-17, 1995.

OLIVI, M.; SANTANA, R.G.; MATHIAS, T.A.F. Comportamento, conhecimento e percepção de risco sobre doenças sexualmente transmissíveis em um grupo de pessoas com 50 anos e mais de idade. Rev Latino-am Enfermagem. Ribeirão Preto, v. 16, n. 4, p. 679-85, 2008.

PEDRAZZANI, E.S. et al. Aspectos educacionais da intervenção em helmintoses intestinais, no Subdistrito de Santa Eudóxia, Município de São Carlos-SP. Cad Saúde Pública. Rio de Janeiro, v. 6, n. 1, p. 74-86, 1990.

PERKINS, R.B. et al. A community-based education program about cervical cancer improves knowledge and screening behavior in Honduran women. Rev Panam Salud Publica. Washington, v. 22, n. 3, p. 187-93, 2007.

PRADO, E.V. Programa de educação em saúde via rádio: percepção do ouvinte. Mundo saúde. São Paulo, v. 31, n. 3, p. 394-402, 2007.

PRADO, E.V. et al. Construindo cidadania: educação popular em saúde via rádio comunitária. Rev APS. Juiz de Fora, v. 14, n. 4, p. 497-501, 2011.

REICHERT, J. et al. Diretrizes para cessação do tabagismo. J. Bras. Pneumol. Brasília, v. 34, n. 10, p. 845-80, 2008.

RODRIGUES, B.C. et al. Educação em Saúde para a Prevenção do Câncer Cérvicouterino. Rev. Bras. Educ. Med. Rio de Janeiro, v. 36, n. 1 Supl 1, p. 149-54, 2012.

SANTOS, B.S. A crítica da razão indolente: contra o desperdício da experiência. São Paulo: Cortez, 2000. 415 p. 
SANTOS, S.L.S.; CABRAL, A.C.S.P.; AUGUSTO, L.G.S. Conhecimento, atitude e prática sobre dengue, seu vetor e ações de controle em uma comunidade urbana do Nordeste. Cienc Saude Colet. Rio de Janeiro, v. 16, supl. 1, p. 1319-30, 2011.

SILVA, R.P. et al. Rádio UNIFESP Web-Desenvolvimento e Implantação de um Modelo para a Disseminação do Conhecimento de Saúde. In: X CONGRESSO BRASILEIRO DE INFORMÁTICA EM SAÚDE, 2006, Florianópolis. Anais... Florianópolis: 2006. p. 167-72. SIQUEIRA, R.V.; FIORINI, J.E. Conhecimentos e procedimentos de crianças em idade escolar frente a parasitoses intestinais. Rev Univ Alfenas. Alfenas, v. 5, p. 215-20, 1999.

VIEIRA, S. Como elaborar questionários. São Paulo: Atlas, 2009. 162 p.

TANNI, S.E. et al. Avaliação do conhecimento sobre tabagismo em pacientes internados. J. Bras. Pneumol. Brasília, v. 36, n. 2, p. 218-23, 2010.

\section{Nota}

${ }^{1}$ M.F. Gazzinelli, L.G. Colares, L.M. Bernardino e L.H.L. Araújo trabalharam na concepção, pesquisa, metodologia, interpretação dos dados e redação final. A.N. Soares trabalhou na metodologia, interpretação dos dados e redação final. 
"Hello, Doctor!": pilot study of radio intervention in Health Education developed in a rural area of Minas Gerais state, Brazil The study aimed to analyze the effects of a Health Education Program developed by undergraduate students of medicine, with the use of radio on the construction of knowledge on the part of listeners from a municipality in Minas Gerais state. It is interventional study, with longitudinal and quantitative approach, performed in the city of Gouveia, located in the central-southern Jequitinhonha Valley, Minas Gerais, Brazil. It was found that the study participants know various aspects of dengue fever, parasites, STD / HIV / AIDS, as well as on the effects of alcohol and tobacco. Also, radio played an important role in learning related to grievances addressed, significantly expanding the percentage of correct questions posed. The considerations indicate that the use of educational strategies legitimized in experiential scenario population and guided in a dialogic relationship is essential for the reconstruction of knowledge based on previous knowledge of the students.

> Key words: health education; radio; dengue; parasitic diseases, sexually transmitted diseases. 